\title{
Fish oil supplementation during adolescence attenuates metabolic programming of perinatal maternal high-fat diet in adult offspring
}

\author{
Aline F. P. Souza ${ }^{1} \dagger$, Luana L. Souza ${ }^{1} \dagger^{*}$, Lorraine S. Oliveira ${ }^{1}$, Aline Cordeiro ${ }^{1}$, Eliete Souza ${ }^{1}$, \\ George E. G. Kluck ${ }^{2}$, Georgia C. Atella ${ }^{2}$, Isis H. Trevenzoli ${ }^{1}$ and Carmen C. Pazos-Moura ${ }^{1}$ \\ ${ }^{1}$ Instituto de Biofísica Carlos Chagas Filho, Universidade Federal do Rio de Janeiro, RJ, Brazil \\ ${ }^{2}$ Instituto de Bioquímica Médica Leopoldo de Meis, Universidade Federal do Rio de Janeiro, RJ, Brazil
}

(Submitted 5 November 2018 - Final revision received 11 March 2019 - Accepted 21 March 2019)

\section{Abstract}

Perinatal maternal high-fat diet (HFD) increases susceptibility to obesity and fatty liver diseases in adult offspring, which can be attenuated by the potent hypolipidaemic action of fish oil (FO), an n-3 PUFA source, during adult life. Previously, we described that adolescent HFD offspring showed resistance to FO hypolipidaemic effects, although FO promoted hepatic molecular changes suggestive of reduced lipid accumulation. Here, we investigated whether this FO intervention only during the adolescence period could affect offspring metabolism in adulthood. Then, female Wistar rats received isoenergetic, standard (STD: $9 \%$ fat) or high-fat (HFD: $28.6 \%$ fat) diet before mating, and throughout pregnancy and lactation. After weaning, male offspring received the standard diet; and from 25 to $45 \mathrm{~d}$ old they received oral administration of soyabean oil or FO. At $150 \mathrm{~d}$ old, serum and hepatic metabolic parameters were evaluated. Maternal HFD adult offspring showed increased body weight, visceral adiposity, hyperleptinaemia and decreased hepatic pSTAT3/ STAT3 ratio, suggestive of hepatic leptin resistance. FO intake only during the adolescence period reduced visceral adiposity and serum leptin, regardless of maternal diet. Maternal HFD promoted dyslipidaemia and hepatic TAG accumulation, which was correlated with reduced hepatic carnitine palmitoyl transferase-1a content, suggesting lipid oxidation impairment. FO intake did not change serum lipids; however, it restored hepatic TAG content and hepatic markers of lipid oxidation to STD offspring levels. Therefore, we concluded that FO intake exclusively during adolescence programmed STD offspring and reprogrammed HFD offspring male rats to a healthier metabolic phenotype in adult life, reducing visceral adiposity, serum leptin and hepatic TAG content in offspring adulthood.

\section{Key words: Maternal high-fat diet: Fish oil intake: Adolescence: Metabolic programming and reprogramming}

The increasing global prevalence of obesity is associated with poor nutritional habits, with increased consumption of high-fat diet (HFD) and high-sugar diet, and sedentarism ${ }^{(1)}$. This inadequate nutrition during the perinatal period, including maternal nutritional status, is also an important contributing factor for the alarming worldwide obesity rates. In humans and experimental models, early life nutritional insults, such as under- or overnutrition during the perinatal period, increase the risk of obesity and its co-morbidities in adult offspring ${ }^{(2)}$. This phenomenon is known as metabolic programming and highlights the intense ontogenetic plasticity in early life, reprogramming gene expression pattern of the offspring to ensure short-term adaptation to the milieu but with detrimental metabolic outcomes throughout life ${ }^{(3,4)}$. This adaptive mechanism involved in early life events and its impact on later risk of chronic diseases is the basis of the developmental origins of health and disease, a new field of study ${ }^{(5)}$.
Maternal obesity during the perinatal period increases offspring adiposity and adipocyte hypertrophy, reflecting in high serum leptin, an important hormone involved in energy metabolism homeostasis $^{(6)}$. Previously, we showed that maternal consumption of isoenergetic HFD during the perinatal period alters breast milk composition and increases body weight, food intake, adiposity, circulating leptin levels associated with impaired leptin signalling at the hypothalamus. Besides that, it alters lipid metabolism in male offspring at weaning ${ }^{(7)}$, adolescence ${ }^{(8)}$ and adult life ${ }^{(9)}$. This metabolic profile increases the susceptibility to develop insulin resistance, dyslipidaemia and non-alcoholic fatty liver disease in the offspring of obese dams, as others have demonstrated ${ }^{(10-12)}$.

Obesity management has been a major challenge in the last decades, and there are very few pharmacological approaches approved by the international organisations ${ }^{(13)}$. In addition, the increasing rates of obesity among children and adolescents ${ }^{(14)}$ require further investigation of possible therapies that could be

Abbreviations: AIN, American Institute of Nutrition; CPT-1a, carnitine palmitoyl transferase-1a; FAS, fatty acid synthase; FO, fish oil; HFD, high-fat diet; SO, soyabean oil; STAT3, signal transducer and activator of transcription 3; STD, standard diet; TSH, thyroid-stimulating hormone.

* Corresponding author: Luana Lopes de Souza, email luana@biof.ufrj.br

$\dagger$ These authors contributed equally to this work. 
beneficial and safe for this critical window of development. Furthermore, obese children and adolescents are frequently inserted into obesogenic environments with poor familiar habits that could have programmed their metabolism since perinatal life $\mathrm{f}^{(15,16)}$. Therefore, it is necessary to investigate potential interventions to prevent or improve metabolic outcomes induced by perinatal maternal dietary choices.

It has been shown that the supplementation of maternal HFD with $n$-3 PUFA attenuates metabolic injury (such as dyslipidaemia, oxidative stress and insulin resistance) in the offspring in adulthood, compared with maternal HFD rich in SFA ${ }^{(17,18)}$. Also, the chronic consumption of $n-3$ PUFA throughout offspring's life reduced metabolic deleterious outcomes (such as hypertension, hyperleptinaemia and glucose intolerance) in experimental programming models ${ }^{(19,20)}$. These metabolic benefits observed with $n$-3 PUFA or fish oil (FO) supplementation are well characterised in adult animal experimental models and humans. FO consumption reduces adiposity and serum lipids in adult rodents ${ }^{(21,22)}$ and humans ${ }^{(23)} \cdot n-3$ PUFA present a hypolipidaemic effect ${ }^{(24,25)}$ by controlling molecular mechanisms involved in the suppression of hepatic lipogenesis and up-regulation of lipid oxidation ${ }^{(25)}$.

We have recently shown that FO intervention in adolescent rats reduced serum lipids only in control offspring but not in those programmed by maternal HFD. This resistance to the hypolipidaemic effect of FO was associated with reduced levels of $n-3$ PUFA in serum of the adolescent rats programmed by maternal HFD ${ }^{(8)}$. Nevertheless, FO intake induced molecular changes in hepatic TAG metabolism suggestive of decreased de novo lipogenesis, in both control- and HFD-adolescent offspring. This raises the question of whether FO intervention during adolescence could impact the offspring metabolism in adulthood. Here we tested the hypothesis that FO intervention during adolescence may prevent or attenuate the higher adiposity, hyperleptinaemia, liver steatosis and dyslipidaemia of adult male offspring programmed by perinatal maternal HFD.

\section{Material and methods}

\section{Ethical statement}

All procedures were approved by the Ethics Committee on Animal Care of the Health Sciences Center, Federal University of Rio de Janeiro (protocol no. IBCCF 140/13), which follows the principles adopted in the UK and Brazil according to Brazilian Law no. $11.794 / 2008^{(26,27)}$.

\section{Experimental animals and procedures}

Wistar rats were obtained from the Center of Reproduction Biology of the Federal University of Rio de Janeiro, Rio de Janeiro, Brazil. They were acclimated and maintained in individual cages with free access to water and food in a room with controlled temperature $\left(23 \pm 2^{\circ} \mathrm{C}\right)$ and $12 \mathrm{~h}$ light $-12 \mathrm{~h}$ darkness cycles (lights on from 07.00 to 19.00 hours). Wistar rats are experimental models frequently used in evaluation of the consequences of metabolic programming ${ }^{(7,8,17,19,20,28)}$, because rodents have short gestation and lactation periods, allowing the rapid evaluation of transgenerational transmission ${ }^{(29)}$. Besides that, genetic and environmental influences can be carefully controlled in these experimental models. The relevance of our study is that this experimental model simulates the increased consumption of HFD and obesity rates among women in reproductive age ${ }^{(30)}$, and its correlation with metabolic obesity among adolescent offspring reported by epidemiological observations ${ }^{(31)}$. Then, our model allows to investigate the perinatal insult impact on phenotype and molecular changes of offspring ${ }^{(29)}$, inferring the molecular mechanism involved in the human observations.

Twenty-six female Wistar rats, $60 \mathrm{~d}$ old and weighing 190-220 g, were randomly distributed in two experimental groups: standard diet (STD) or HFD (thirteen per group). The STD group received an STD for rodents ( $9 \%$ of the energy as fat), and HFD group received an HFD (28.6 \% of the energy as fat - lard was used as the major fat source) for 8 weeks before mating and during pregnancy and lactation ${ }^{(7)}$. During mating, two female rats of the same group were housed with one male rat $(150 \mathrm{~d}$ old). After this, female rats were housed in individual cages during pregnancy and lactation to avoid stressful environment. The maternal comportment was evaluated, and the maternal stress was discarded by absence of killed puppies by dams. At birth, litters were adjusted to six males for each dam aiming to improve lactation performance ${ }^{(32)}$. STD and HFD offspring received STD (the same perinatal STD) during the postnatal period, from weaning (21 d old) until adulthood (150 d old).

Our HFD is moderately high-fat compared with most experimental models that generally use diets with $50 \%$ of the energy as fat ${ }^{(28,33)}$. The HFD was manually produced in our laboratory using the ingredients described at Table 1, including the commercial STD chow. Diet composition followed the American Institute of Nutrition recommendations (AIN-93) for micronutrients $^{(34)}$ and was described before ${ }^{(7-9)}$. Both diets contained approximately $16.3 \mathrm{~kJ} / \mathrm{g}$ of energy (isoenergetic) and their macronutrients compositions are described at Table 2. The HFD was composed by a moderate increased lipid content with protein and carbohydrate contents within the range recommended for rodents (AIN-93), which avoided the negative impact of lowprotein or low-carbohydrate diets ${ }^{(35,36)}$. The differences between macronutrient compositions of diets were not tested statistically, because we estimated the diet composition by ingredients

Table 1. Diet composition $(\mathrm{g} / \mathrm{kg})$ on the basis of the American Institute of Nutrition (AIN)-93G diet formulation

\begin{tabular}{lc}
\hline Ingredient & HFD $(\mathrm{g} / \mathrm{kg})$ \\
\hline Standard chow powder & 150 \\
Sweet condensed milk & 395 \\
Fat-free dry milk & 280 \\
Maize starch & 150 \\
Lard & 80 \\
Soyabean oil & 10 \\
AIN-93G mineral mix & 29 \\
AIN-93G vitamin mix & 8 \\
L-Cystine & $2 \cdot 625$ \\
Choline bitartrate & 0.82 \\
BHT & $0 \cdot 1$ \\
\hline HFD, high-fat diet; BHT, butylated hydroxytoluene.
\end{tabular}


Table 2. Diet macronutrient composition

\begin{tabular}{|c|c|c|c|}
\hline Macronutrients & $g$ & $\mathrm{kcal}^{*}$ & $\%$ energy \\
\hline \multicolumn{4}{|c|}{ Standard diet (amount per $\mathrm{kg}$ ) } \\
\hline Protein & 220 & 880 & $22 \cdot 6$ \\
\hline Lipids & 40 & 360 & 9.4 \\
\hline Carbohydrates & 660 & 2640 & 68 \\
\hline Total & 1000 & 3880 & 100 \\
\hline \multicolumn{4}{|c|}{ High-fat diet (amount per kg) } \\
\hline Protein & $169 \cdot 6$ & 678.4 & $17 \cdot 3$ \\
\hline Lipids & 214.9 & 1124 & 28.6 \\
\hline Carbohydrates & $530 \cdot 3$ & 2121 & $54 \cdot 1$ \\
\hline Total & 1092 & 3923 & 100 \\
\hline
\end{tabular}

* To convert kcal to kJ, multiply by 4.184 .

Table 3. Fatty acid composition of the experimental diets ( $\mu \mathrm{g} / \mathrm{mg}$ of chow)

\begin{tabular}{|c|c|c|c|}
\hline Fatty acid $(\mu \mathrm{g} / \mathrm{mg})$ & STD & HFD & $P$ \\
\hline C10: 0 & N.D. & $2 \cdot 141$ & $<0.01$ \\
\hline C12: 0 & 0.054 & 0.825 & $<0.01$ \\
\hline C13: 0 & N.D. & 0.019 & $<0.01$ \\
\hline C14:1 & N.D. & 0.233 & $<0.01$ \\
\hline C14: 0 & 0.186 & 2.586 & $<0.01$ \\
\hline C15: 0 & N.D. & 0.261 & 0.0001 \\
\hline $\mathrm{C} 16: 1$ & 0.112 & 1.350 & 0.0001 \\
\hline C16: 0 & 9.868 & 18.425 & $<0.05$ \\
\hline C17: 1 & N.D. & 0.194 & $<0.001$ \\
\hline C17: 0 & 0.069 & 0.742 & $<0.05$ \\
\hline C18: $2 n-6$ cis & $26 \cdot 609$ & $16 \cdot 214$ & 0.08 \\
\hline C18: $1 n-9$ cis & $12 \cdot 282$ & $16 \cdot 634$ & $0 \cdot 18$ \\
\hline C18: $1 n-9$ trans & 0.815 & 1.692 & $<0.01$ \\
\hline C18: 0 & 1.534 & 8.804 & 0.0001 \\
\hline C19: 0 & 0.290 & 0.300 & 0.61 \\
\hline $\mathrm{C} 20: 4 n-6$ & 0.07 & 0.189 & $<0.001$ \\
\hline $\mathrm{C} 20: 3 n-6$ & N.D. & 0.120 & $<0.001$ \\
\hline $\mathrm{C} 20: 2 n-6$ & 0.024 & 0.384 & $<0.01$ \\
\hline $\mathrm{C} 20: 1 n-9$ & 0.165 & 0.323 & $<0.01$ \\
\hline C20 : 0 & 0.239 & 0.196 & 0.28 \\
\hline $\mathrm{C} 21: 0$ & 0.010 & 0.008 & 0.48 \\
\hline $\mathrm{C} 22: 6 n-3$ & 0.001 & 0.061 & 0.07 \\
\hline $\mathrm{C} 22: 1 n-9$ & 0.052 & 0.020 & $<0.05$ \\
\hline C22 : 0 & 0.203 & 0.083 & 0.06 \\
\hline $\mathrm{C} 23: 0$ & 0.041 & 0.034 & 0.65 \\
\hline $\mathrm{C} 24: 1 n-9$ & 0.049 & N.D. & 0.37 \\
\hline C24: 0 & 0.294 & 0.074 & $<0.05$ \\
\hline SFA & $12 \cdot 789$ & 34.499 & $<0.01$ \\
\hline MUFA & $13 \cdot 384$ & $25 \cdot 148$ & 0.15 \\
\hline PUFA & $26 \cdot 640$ & $16 \cdot 968$ & 0.09 \\
\hline$n-3$ & 0.001 & 0.061 & 0.12 \\
\hline$n-6$ & $26 \cdot 640$ & $16 \cdot 907$ & 0.09 \\
\hline
\end{tabular}

STD, standard diet; HFD, high-fat diet; N.D., not detected.

* Fatty acids were quantified by GC/MS determining peak-area ratios with the $9: 0$ and 19: 0 internal standards. We used three samples per group.

composition described at ingredient label. The fatty-acid compositions of diets were analysed by gas chromatography. The HFD showed higher SFA content than STD $(P<0 \cdot 01)$, and its detailed fatty-acid composition is described at Table 3.

In the adolescence period ${ }^{(37)}$, two male rats of each litter were randomly allocated at soyabean oil (SO) or FO group in individual cages. The remaining pups were used in another experimental design ${ }^{(8)}$. Then, the experimental design had four experimental groups: STD or HFD offspring that received SO (source of $n$-6 PUFA; Liza®, Cargill) ( $n 12$ and 9, respectively) and STD or HFD offspring that received FO (source of $n-3$ PUFA; Fagron) ( $n 12$ and 9, respectively). Oil administration was given daily by gavage ( $4 \mathrm{ml} / \mathrm{kg}$ body weight) from 25 to $45 \mathrm{~d}$ old. Each capsule of FO had $95.5 \mathrm{mg} / \mathrm{ml}$ of EPA and $61 \mathrm{mg} / \mathrm{ml}$ of DHA, resulting in a dose of $0 \cdot 244 \mathrm{~g} / \mathrm{kg}$ of DHA and $0.380 \mathrm{~g} / \mathrm{kg}$ per $\mathrm{d}$. This DHA dose adjusted to human ${ }^{(38)}$ is in a dose range used in human experimental design with FO supplementation during the adolescence period ${ }^{(39-41)}$. SO was used as control to exclude lipid load effect, ensuring that the results are derived from the different types of fatty acids used in the treatment. Furthermore, SO is a lipid source recommended for rodents according to the AIN-93 ${ }^{(34)}$, and represents the main fatty acid present in the Western diet ( $n$-6 PUFA) ${ }^{(42)}$.

We performed an oral glucose tolerance test with the animals at $147 \mathrm{~d}$ of age. After 12-h fasting, capillary blood glucose was measured from a tail incision, followed by oral glucose (D- (+) -glucose; VETEC) administration ( $2 \mathrm{mg} / \mathrm{g}$ of body weight). Glycaemia was also measured at 15, 30, 60 and 90 min after glucose administration (One Touch Ultra Mini device; Johnson and Johnson).

During the experiment, we did not observe adverse events or features of stressed animals, such as aggressive behaviour, hair loss or body weight loss. At $150 \mathrm{~d}$ of age, rats were killed by decapitation. Serum was obtained from trunk blood (after centrifugation at $1000 \mathrm{~g}, 4^{\circ} \mathrm{C}, 20 \mathrm{~min}$ ) and kept frozen at $-20^{\circ} \mathrm{C}$ for measurements of hormone levels and biochemical parameters. Representative depots of visceral white adipose tissue (retroperitoneal and epididymal) were dissected, weighed and returned to eviscerated carcass, to evaluate the adiposity. Liver was harvested, snap frozen in liquid nitrogen and stored at $-70^{\circ} \mathrm{C}$ prior to extraction of total lipid, protein and RNA.

\section{Fatty-acid composition of the experimental diets}

The GC/MS assay was used to investigate the fatty-acid profile in experimental diets (STD and HFD). The lipid sample was dissolved in a toluene and $1 \%$ sulfuric acid in methanol solution. GC/MS analysis was carried out on a Shimadzu GCMS-QP2010 Plus system, using an HP Ultra 2 (5\% phenyl-methylpolysiloxane), Agilent $(25 \mathrm{~m} \times 0.20 \mathrm{~mm} \times 0.33 \mu \mathrm{m})$. Injector was set at $250^{\circ} \mathrm{C}$. Column temperature was programmed from 40 to $160^{\circ} \mathrm{C}$ at $30^{\circ} \mathrm{C} / \mathrm{min}, 160$ to $233^{\circ} \mathrm{C}$ at $1^{\circ} \mathrm{C} / \mathrm{min}, 233$ to $300^{\circ} \mathrm{C}$ at $30^{\circ} \mathrm{C} / \mathrm{m}$ and held at $300^{\circ} \mathrm{C}$ for $10 \mathrm{~min}$. Electro ionisation (EI-70 eV) and a quadrupole mass analyser operated in scans from 40 to 440 atomic mass units. Interface was set at $240^{\circ} \mathrm{C}$ and the ion source at $240^{\circ} \mathrm{C}$. The components were identified by comparing their mass spectra with those of the library NIST05 contained in the computer's mass spectrometer. Retention indices were also used to confirm the identity of the peaks in the chromatogram by Supelco 37 Component FAME Mix (Sigma-Aldrich). Fatty acids were quantified by determining peak-area ratios with the 9:0 and 19:0 internal standards. We used three samples per group.

\section{Body composition analysis}

Total body lipid quantification was performed as previously described $^{(43,44)}$. Briefly, eviscerated carcasses were weighed, autoclaved and homogenised in distilled water (1:1). Homogenate $(3 \mathrm{~g})$ was hydrolysed in a shaking water bath at 
$70^{\circ} \mathrm{C}$ for $2 \mathrm{~h}$ with $30 \% \mathrm{KOH}$ and ethanol, followed by three successive washes with petroleum ether (Vetec) to extract lipids. The petroleum ether phases containing the lipids were dried at room temperature until constant weight was obtained.

\section{Serum lipid profile}

Serum total cholesterol (no. 12505), HDL-cholesterol (no. 12557) and TAG (no. 12528) quantification was performed using commercial kits from Biosystems and an automated A15 spectrophotometer (Biosystems S.A.). The serum VLDL-cholesterol and LDL-cholesterol were estimated according to the Friedewald assumption ${ }^{(45)}: \quad \mathrm{VLDL}=\mathrm{TAG} / 5$ and $\mathrm{LDL}=$ total cholesterol - HDL - TAG/5.

\section{Hormone assays}

Serum leptin was measured using specific commercial radioimmunoassay (RIA) kit from Linco Research (no. XL-85K). Total serum thyroxine and total serum triiodothyronine were determined using specific commercial RIA kits from MP Biomedicals (no. 06B-254011 and no. 06B-254215). Serum thyroid-stimulating hormone (TSH) was measured by a specific rat TSH RIA using reagents acquired from the National Hormone and Pituitary Program, as previously detailed ${ }^{(46)}$. Serum adiponectin was measured by a specific rat Adiponectin ELISA Kit from Merck Millipore (no. EZRADP-62K). All samples were evaluated in duplicate within the same assay according to the manufacturer's instructions.

\section{Real-time $P C R$ analysis}

Real-time PCR assay was used to evaluate the relative mRNA expression of genes encoding PPAR $\alpha$ (Ppara), hepatic lipase (LipC), carnitine palmitoyl transferase-1a (CPT-1a: Cpt1a),

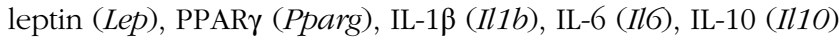
and TNF- $\alpha$ (Tnf).

Total RNA was isolated from retroperitoneal adipose tissue samples using a commercial RNeasy lipid tissue mini kit (Qiagen), and from liver samples using a commercial SV Total RNA Isolation System (Promega). Total RNA was reverse transcribed using $1 \mu \mathrm{g}$ of total RNA and a High-Capacity cDNA Reverse Transcription Kit (Applied Biosystems). Products were amplified on Eppendorf MasterCycler RealPlex (Eppendorf) using Maxima SYBR Green qPCR Master Mix (Thermo Scientific). Cycle parameters were $50^{\circ} \mathrm{C}$ for $2 \mathrm{~min}$ and $95^{\circ} \mathrm{C}$ for
$10 \mathrm{~min}$, followed by forty cycles at $95^{\circ} \mathrm{C}$ for $15 \mathrm{~s}, 60^{\circ} \mathrm{C}$ for $30 \mathrm{~s}$, and $72^{\circ} \mathrm{C}$ for $45 \mathrm{~s}$. The intron spanning primers sequence used in the present study are described in Table 4. Primers were synthesised and tested by Integrated DNA Technologies. Samples and negative controls were evaluated in duplicate in the same assay. Efficiency of each PCR reaction was calculated using a serial cDNA dilution standard curve, and varied from 96 to $100 \%$. Product purity was confirmed by a single peak in the melting curve analysis. Relative mRNA levels were calculated using standard curve method and normalised by mRNA levels of the reference genes Polr2a (liver) or RplpO mRNA (adipose tissue). Results are expressed relative to values of control group (STD offspring that received SO during the adolescence period).

\section{Western blotting analysis}

We used the Western blotting assay to evaluate the hepatic content of fatty acid synthase (FAS), CPT-1a, and signal transducer and activator of transcription 3 (STAT3 and pSTAT3). The content of cyclophilin (Cyclo) or glyceraldehyde3-phosphate dehydrogenase (GAPDH) was used as loading control. Liver samples were homogenised in lyses buffer pH 6.4 (50-mm HEPES, 1-mm $\mathrm{MgCl}_{2}, 10$-nм EDTA, and $1 \%$ Triton X) with protease inhibitor cocktail complete (Roche Diagnostics). After centrifugation of the homogenates, the total protein content of the supernatant was quantified using the Pierce $^{\mathrm{TM}}$ BCA Protein assay kit (Thermo Scientific). Total protein was separated by SDS-PAGE and transferred onto a polyvinylidene difluoride membrane (Hybond-P $0.45 \mu \mathrm{m}$ PVDF; Amersham Biosciences). Membrane was blocked with 5\% non-fat dry milk (Molico, Nestlé) or $5 \%$ bovine serum albumin (INLAB) according to the protein of interest for $1 \mathrm{~h}$ at room temperature. Then, membrane was incubated overnight at $4^{\circ} \mathrm{C}$ with primary antibodies: anti-FAS (Cell Signaling; 1:1000 dilution), anti-CPT-1a (Abcam; 1:3000 dilution), anti-STAT3 (Santa Cruz; 1:400), anti-pSTAT (Santa Cruz; 1:1600) and loading control anti-Cyclo (Thermo Scientific; 1:40 000 dilution) or antiGAPDH (Cell Signaling; 1:3000 dilution). Membranes were washed and incubated with peroxidase-labelled anti-rabbit IgG antibody (Amersham Biosciences, BKM, England; 1:10 000 dilution) or anti-mouse IgG antibody (Cell Signaling; $1: 10000$ ) for $3 \mathrm{~h}$ at room temperature. All blots were then washed and incubated with a luminogen detection reagent (Amersham ECL Prime Western Blotting Detection reagent;

Table 4. Primer sequences for gene expression evaluation

\begin{tabular}{|c|c|c|}
\hline Gene & Sense & Antisense \\
\hline Tnfa & 5'-GTCTTTGAGATCCATGCCATTG-3' & 5'-AGACCCTCACACTCAGATCA-3' \\
\hline 116 & 5'-CCTTCTGTGACTCTAACTTCTCC-3' & 5'-CAGAGCAATACTGAAACCCTAGT-3' \\
\hline $1 / 10$ & 5'-TGGCCTTGTAGACACCTTTG-3' & 5'-CGACGCTGTCATCGATTTCTC-3' \\
\hline$\| 1 b$ & 5'-TTGTCGTTGCTTGTCTCTCC-3' & 5'-GTGCTGTCTGACCCATGT-3' \\
\hline Rplpo & 5'-TGTCTGCTCCCACAATGAAG-3' & 5'-CAATCCCTGACGCACCG-3' \\
\hline Lep & 5'-CCATCTTGGACAAACTCAGAATG-3' & 5'-GACCATTGTCACCAGGATCA-3' \\
\hline Cpt1 & $5^{\prime}$-GAGCCAGACCTTGAAGTACC-3' & 5'-AGCGACTCTTCAATACTTCCC-3' \\
\hline Lipc & 5'-AGATCCAGTCCACTAATCCCA-3' & 5'-GCTCCCATCCACTTGTCAT-3' \\
\hline Ppara & 5'-TTCAATGCCCTCGAACTGGA-3' & 5'-GCACAATCСССТССТGСАAC-3' \\
\hline Polr2a & 5'-TCTGCCAAGAATGTGACGCT-3' & 5'-CCAAGCGGCAAAGAATGTCC-3' \\
\hline
\end{tabular}


Amersham Biosciences or SuperSignal@ West Femto Maximum Sensitivity Substrate; Thermo Scientific). Chemiluminescent signal was detect by ImageQuant LAS 4000 equipment followed by densitometric analyses (GE Healthcare Life Sciences).

\section{$T L C$}

Liver total lipids were extracted by the method of Bligh \& Dyer $^{(47)}$ with modifications. After incubation in chloroformmethanol-water solution (2:1:0.4, by vol.), samples were centrifuged (1500 $\boldsymbol{g}$ for $20 \mathrm{~min}$ at $4^{\circ} \mathrm{C}$ ). Then, the chloroform was added to the supernatant. After centrifugation (1500 $\boldsymbol{g}$ for $20 \mathrm{~min}$ ) the organic phase was removed and dried in nitrogen. The extracted lipids were analysed by TLC for neutral lipids, using a DC Silicagel 60 plate (Merck Millipore) and standards lipids. The plates were submerged for $10 \mathrm{~s}$ in Charring solution (3\% $\mathrm{CuSO}_{4}$ and $\left.8 \% \mathrm{H}_{3} \mathrm{PO}_{4}(\mathrm{v} / \mathrm{v})\right)$, then they were dried and heated to $110^{\circ} \mathrm{C}$ for $5-10 \mathrm{~min}$. TLC plates were analysed by densitometry (GE Healthcare Life Sciences), defining hepatic free cholesterol, NEFA and TAG content.

\section{Statistical analysis}

The sample size was calculated by using the G*Power 3.1.9.2 program $^{(48)}$, based in our previous observations of maternal HFD effect on plasma and molecular parameters of the adult offspring $^{(9)}$ and our previous observations of FO intake effect on plasma and molecular parameters in adolescents rats ${ }^{(8)}$. Regarding plasma parameters, a sample size of nine animals per group would provide the appropriate power $(1-\beta=0 \cdot 8)$ to identify significant differences $(\alpha=0.05)$ in the variables analysed, using a two-tailed test. For molecular parameters, a sample size of six animals per group would provide the appropriate power $(1-\beta=0 \cdot 8)$ to identify significant differences $(\alpha=0.05)$ in the variables analysed, using a twotailed test. The statistical comparisons were performed using the software GraphPad Prism (GraphPad Software Inc.) showing results as means with their standard errors. Two-way ANOVA were used considering two variables (maternal diet and oil intervention) and significant differences at $P<0.05$. Tukey's post-test was used to evaluate differences between columns in only each maternal condition. In each analysis of post-test, we corrected the result for multiple comparisons using statistical hypothesis testing and reported multiplicity adjusted $P$ value for each comparison, using a confidence level of 0.05 . To data correlation analysis, normality was assessed by the Kolmogorov-Smirnov test, followed by nonparametric Spearman's correlation test.

\section{Results}

Maternal HFD increased body weight (1.09-fold; $P<0.0001$; Fig. 1(A)), food intake (1.08-fold; $P<0 \cdot 0001$; Fig. 1(B)), retroperitoneal adiposity (1.33-fold; $P<0 \cdot 01$; Fig. $1(\mathrm{C}))$ and total body fat (1.21-fold; $P<0.01$; Fig. 1(D)) of adult male offspring. Regardless of maternal diet, FO intake in the adolescence period did not change body weight or food intake in adulthood (Fig. 1(A) and 1(B)), but it decreased retroperitoneal adipose tissue mass (approximately 19\%, $P<0 \cdot 05$; Fig. $1(\mathrm{C})$ ) and showed a tendency to reduce total body fat in adult offspring $(P=0 \cdot 06$; Fig. 1(D)).

Because we observed maternal diet and FO effects on adiposity of adult offspring, we evaluated adipose tissue gene expression. There was no effect of maternal HFD neither of FO on PPAR- $\gamma$, IL-1b, IL- 6 , IL-10 and TNF- $\alpha$ mRNA expression (data not shown), but maternal HFD promoted 1.6-fold increase in leptin mRNA expression in retroperitoneal adipose tissue $(P<0 \cdot 05$; Fig. 2(A)). This increased leptin mRNA expression was accompanied by approximately 1.75 -fold increase in serum leptin of the maternal HFD offspring $(P<0 \cdot 05$; Fig. 2(B)). Interestingly, the $\mathrm{FO}$ intake during adolescence could attenuate the mRNA expression and serum levels of leptin in both STD and HFD adult offspring $(P<0.05$; Fig. 2(A) and 2(B)). Concomitantly, in the liver, the pSTAT3/STAT3 protein content ratio, which is an important intracellular mediator of leptin action, was significantly reduced in maternal HFD adult offspring $(P<0 \cdot 01)$, but it was not affected by FO intake (Fig. 2(C)).

Maternal HFD did not change serum adiponectin, serum TSH and serum thyroid hormones triiodothyronine and thyroxine, but the offspring that received FO during adolescence showed approximately $18 \%$ reduced serum triiodothyronine in adult life, regardless of the maternal diet (Table 5).

Maternal HFD did not change oral glucose tolerance (Table 5), but promoted dyslipidaemia in adult offspring. We observed increased serum TAG (1.24-fold; $P<0.05$; Fig. 3(A)), serum total cholesterol (1.12-fold; $P<0 \cdot 01$; Fig. 3(B)), HDL and VLDL, without changes in serum LDL (Table 5) in adult offspring from HFD dams. However, these metabolic parameters were not changed by FO intake during adolescence of these animals.

Because FO and leptin are known to regulate hepatic lipid metabolism, we investigated lipid metabolism markers in the liver of adult offspring. Maternal HFD promoted higher liver weight (1.14-fold; $P<0 \cdot 0001$; Fig. $3(\mathrm{C}))$, and it was reduced in $10 \%$ by FO intake in STD offspring but not that of HFD group $(P<0.05$; Fig. $3(\mathrm{C}))$. Both maternal HFD and FO intake during adolescence decreased hepatic content of free cholesterol (Fig. 3(D)) in adult offspring. However, neither maternal HFD nor FO intake during adolescence changed hepatic cholesterol ester content (data not shown). FO intake reduced hepatic NEFA content $(P<0 \cdot 05$; Fig. 3(E)), regardless of maternal diet. Interestingly, maternal HFD promoted 1.6-fold higher hepatic TAG content in adult offspring, which was restored to STD offspring levels by FO intake during adolescence of these animals (Fig. 3(F)). FO intake during adolescence reduced hepatic TAG content in approximately $29-40 \%$, independent of maternal diet (Fig. 3(F)).

We investigated the hepatic content of key enzymes of lipid synthesis and oxidation pathways. Although we did not observe statistically significant differences among experimental groups in hepatic FAS and CPT-1a protein abundance (Fig. 4(A) and $4(\mathrm{~B}))$, the maternal HFD offspring showed a strong trend to decreased CPT-1a protein abundance $(P=0 \cdot 07$; Fig. $4(\mathrm{~B}))$. We observed a significant negative correlation among hepatic CPT1a protein abundance and hepatic TAG content $(P<0.05$; Fig. $4(C)$ ), suggesting that impairment in lipid oxidation pathway 


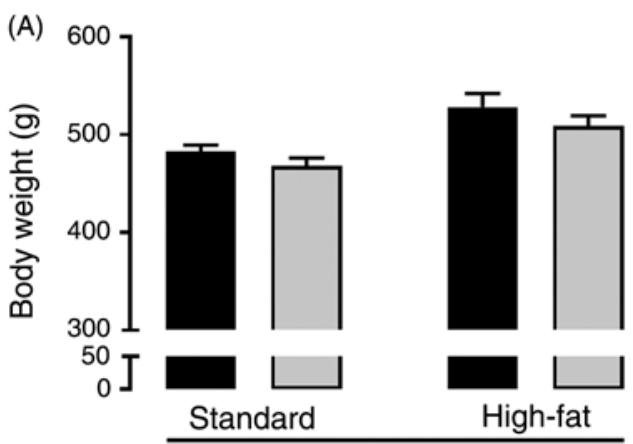

Maternal diet

\begin{tabular}{|l|c|}
\hline Source of variation & $P$ \\
\hline Maternal diet effect & $<0.0001$ \\
\hline Fish oil effect & 0.09 \\
\hline Interaction & 0.83 \\
\hline
\end{tabular}

(C)

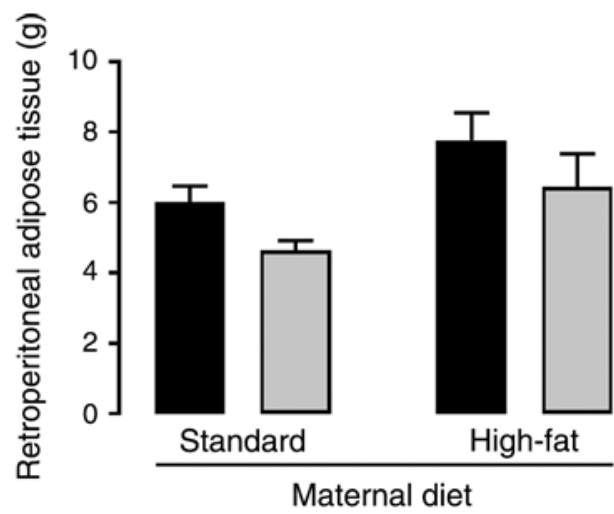

Source of variation

$P$

\begin{tabular}{|l|c|}
\hline Maternal diet effect & $<0.01$ \\
\hline Fish oil effect & $<0.05$ \\
\hline Interaction & 0.98 \\
\hline
\end{tabular}

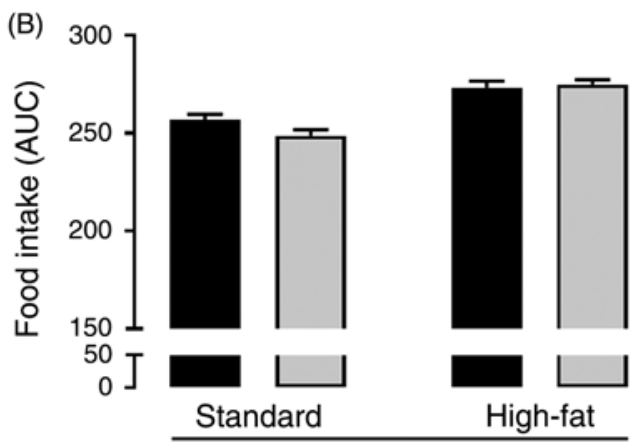

Maternal diet

\begin{tabular}{|l|c|}
\hline Source of variation & $P$ \\
\hline Maternal diet effect & $<0.0001$ \\
\hline Fish oil effect & 0.28 \\
\hline Interaction & 0.11 \\
\hline
\end{tabular}

(D)

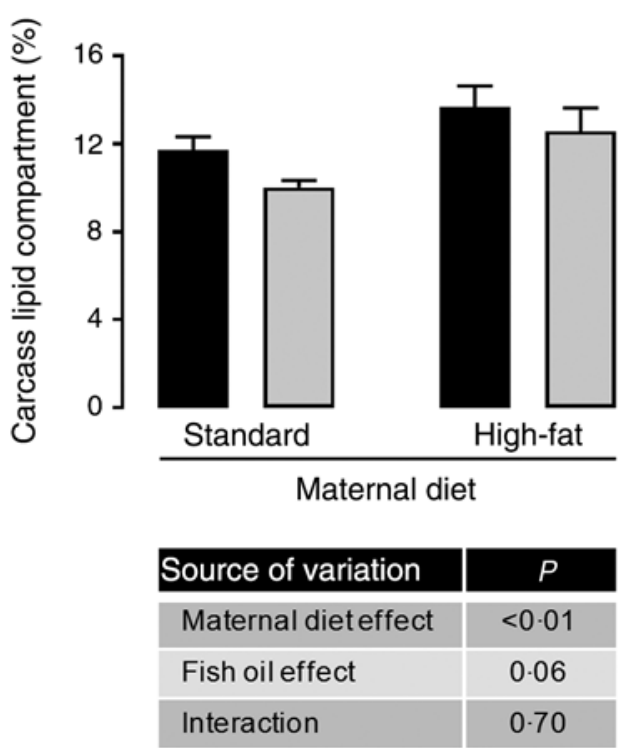

Fig. 1. Effects of fish oil consumption during the adolescence period on adult male offspring from dams that received a standard or high-fat diet. Offspring received daily oral intervention with soyabean oil $(\square)$ or fish oil $(\square)$ from 25 to $45 \mathrm{~d}$ of age, and evaluations were performed in adult life (150 d old). (A) Body weight at $150 \mathrm{~d}$ old. (B) Food intake after oil withdraw (AUC). (C) Retroperitoneal adipose tissue mass. (D) Carcass lipid compartment. Data are means, with their standard errors represented by vertical bars $(n 9-12)$. Statistical analysis was performed using two-way ANOVA and is described in the table at the bottom of each graph, considering significant differences at $P<0.05$.

could be involved in hepatic TAG accumulation. mRNA levels of hepatic CPT-1, hepatic lipase (Lipc) and PPAR- $\alpha$ showed the same profile of CPT-1a protein abundance, however there were no statistical significant differences among the experimental groups (Fig. 4(D), 4(E) and 4(F)).

\section{Discussion}

In the present study, we originally demonstrated that FO consumption just during the adolescence period was able to reprogramme offspring metabolism in adult life, improving metabolic outcomes induced by perinatal maternal HFD. We showed attenuation of visceral adiposity, serum leptin and hepatic TAG that could contribute to a healthier life of adult offspring. These observations suggest the adolescence as a critical period in which dietary choices may impact adult health, revealing a critical window susceptible to metabolic reprogramming.

In the present study, maternal HFD and STD were isoenergetic, and HFD was moderately high-fat compared with other maternal HFD models ${ }^{(28,33)}$. We have been showing that moderate maternal HFD consumption during perinatal life increases body weight, adiposity and leptin levels in male offspring at weaning ${ }^{(7)}$, adolescence ${ }^{(8)}$ and $180 \mathrm{~d}_{\text {old }}{ }^{(9)}$, and here the same profile was observed at $150 \mathrm{~d}$ old. In experimental models of obesity, $n$-3 PUFA consumption decreases adiposity and serum lipids ${ }^{(22,49)}$. However, these beneficial effects are usually 
(A)

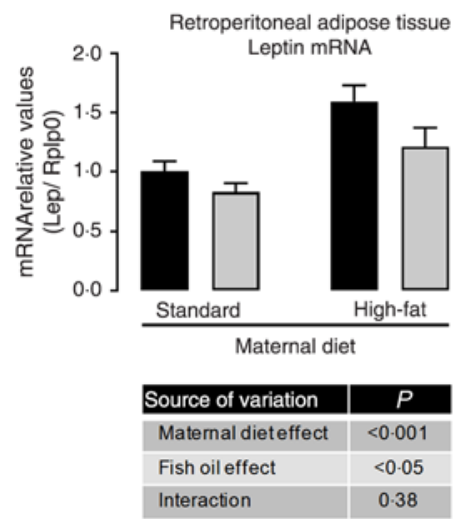

(B)

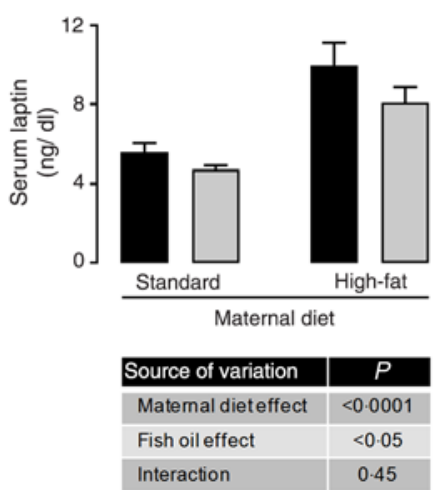

(C)

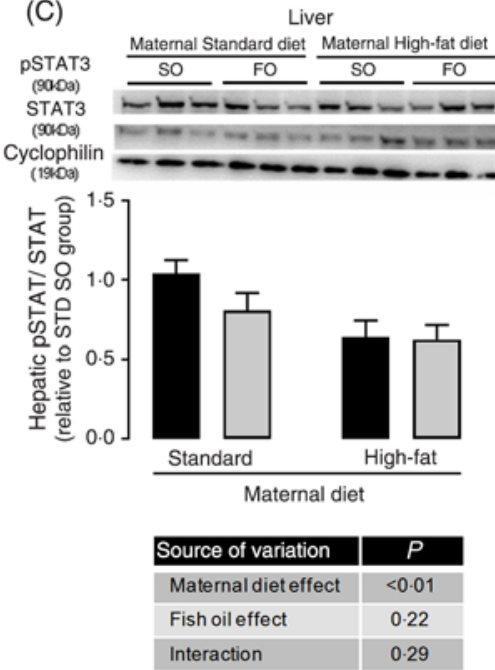

Fig. 2. Effects of fish oil consumption during the adolescence period on leptin levels and hepatic signalling in adult male offspring from dams that received a standard (STD) or high-fat diet. Offspring received daily oral intervention with soyabean oil (SO; ${ }^{-}$) or fish oil (FO; ) from 25 to 45 d of age, and evaluations were performed in adult life (150 d old). (A) mRNA expression of leptin (Lep) in retroperitoneal adipose tissue. (B) Serum leptin levels. (C) Hepatic pSTAT/STAT ratio by Western blotting analysis. Data are means, with their standard errors represented by vertical bars $(n 8-10)$. Statistical analysis was performed using two-way ANOVA and is described in the table at the bottom of each graph, considering significant differences at $P<0.05$. To convert leptin in $\mathrm{ng} / \mathrm{dl}$ to $\mathrm{ng} / \mathrm{l}$, multiply by 10 .

Table 5. Effects of fish oil (FO) consumption during the adolescence period on serum hormones and on metabolic parameters of adult male offspring from dams that received a standard or high-fat diet*

(Mean values with their standard errors; $n 9-12$ )

\begin{tabular}{|c|c|c|c|c|c|c|c|c|c|c|c|}
\hline \multirow[b]{3}{*}{ Serum measurements } & \multicolumn{4}{|c|}{ Maternal standard diet } & \multicolumn{4}{|c|}{ Maternal high-fat diet } & \multirow{3}{*}{$\begin{array}{l}\text { Maternal } \\
\text { diet effect }\end{array}$} & \multirow[b]{3}{*}{ FO effect } & \multirow[b]{3}{*}{ Interaction } \\
\hline & \multicolumn{2}{|c|}{ SO } & \multicolumn{2}{|c|}{$\mathrm{FO}$} & \multicolumn{2}{|c|}{ so } & \multicolumn{2}{|c|}{$\mathrm{FO}$} & & & \\
\hline & Mean & SEM & Mean & SEM & Mean & SEM & Mean & SEM & & & \\
\hline Adiponectin (ng/ml) & 12220 & 2168 & 13150 & 2341 & 12403 & 2231 & 13810 & 2966 & No & No & No \\
\hline Triiodothyronine $(\mathrm{ng} / \mathrm{dl}) \dagger$ & $70 \cdot 7$ & 4.0 & $57 \cdot 3$ & 4.3 & $64 \cdot 3$ & $7 \cdot 2$ & $53 \cdot 3$ & $5 \cdot 1$ & No & $P<0.05$ & No \\
\hline Thyroxine $(\mu \mathrm{g} / \mathrm{dl}) \dagger$ & 5.02 & 0.15 & 4.92 & 0.16 & 4.92 & 0.26 & 4.93 & 0.24 & No & No & No \\
\hline Thyroid-stimulating hormone (ng/ml) & $3 \cdot 30$ & 1.40 & $3 \cdot 27$ & 1.52 & 2.93 & 0.73 & $4 \cdot 18$ & $2 \cdot 47$ & No & No & No \\
\hline AUC OGTT (arbitrary units) & 15262 & 287 & 14797 & 194 & 14803 & 307 & 14251 & 427 & No & No & No \\
\hline HDL-cholesterol $(\mathrm{mg} / \mathrm{dl}) \dagger$ & 33.5 & $4 \cdot 1$ & 31.9 & 4.5 & $37 \cdot 2$ & $7 \cdot 0$ & $35 \cdot 1$ & 3.4 & $P<0.05$ & No & No \\
\hline LDL-cholesterol $(\mathrm{mg} / \mathrm{dl}) \dagger$ & $14 \cdot 8$ & $2 \cdot 0$ & $19 \cdot 8$ & 3.1 & $9 \cdot 3$ & $5 \cdot 4$ & $15 \cdot 8$ & $2 \cdot 5$ & No & No & No \\
\hline VLDL-cholesterol $(\mathrm{mg} / \mathrm{dl}) \dagger$ & $26 \cdot 3$ & $6 \cdot 9$ & $21 \cdot 6$ & $6 \cdot 9$ & $31 \cdot 3$ & 13.5 & $27 \cdot 8$ & $6 \cdot 9$ & $P<0.05$ & No & No \\
\hline
\end{tabular}

SO, soyabean oil; OGTT, oral glucose tolerance test.

* Statistical analysis was performed using two-way ANOVA.

† To convert triiodothyronine in $\mathrm{ng} / \mathrm{dl}$ to $\mathrm{ng} / \mathrm{l}$, multiply by 10 . To convert thyroxine in $\mu \mathrm{g} / \mathrm{dl}$ to $\mu \mathrm{g} / \mathrm{l}$, multiply by 10 . To convert cholesterol in $\mathrm{mg} / \mathrm{dl}$ to $\mathrm{mmol} / \mathrm{l}$, multiply by 0.0259 .

observed during or at the end of treatment. In contrast, we previously showed that FO consumption during adolescence did not change body weight, adiposity or serum leptin in STD or HFD offspring right after the intervention ${ }^{(8)}$. Interestingly, in the present study, we showed that FO intervention during adolescence, independent of maternal diet, promoted long-term effects, reducing visceral adiposity and serum leptin in adult life.

Dyslipidaemia is a common finding of many metabolic programming models ${ }^{(50,51)}$. However, in our maternal HFD model we did not observe dyslipidaemia in adolescent offspring, neither changes in liver TAG content ${ }^{(8)}$, but they presented a molecular profile suggestive of hepatic lipid metabolism impairment, with increased sterol regulatory-element binding protein 1 and acetyl CoA carboxylase expression, reduced CPT-1a content, and decreased ATP binding cassette subfamily G member 8 expression in liver $^{(8)}$. We suggest that these early hepatic molecular changes primed for dyslipidaemia progression during adult life, as we observed here in HFD offspring at $150 \mathrm{~d}$ of age.

Adult HFD offspring showed increased hepatic TAG content, which may progress to hepatoesteatosis ${ }^{(52)}$. This metabolic profile was improved by FO consumption during adolescence, since it restored the hepatic TAG content to STD offspring levels. The mechanism probably involves multiple FO actions. Here we observed in the liver of adult HFD offspring a trend to reduction of CPT- $1 \mathrm{a}$, hepatic lipase and PPAR- $\alpha$ expressions, suggesting impairment of lipid oxidation which seems to be prevented by FO intake during the adolescence. Supporting the hypothesis of increased lipid oxidation as a potential target mechanism for FO in this model, we found a negative correlation between hepatic CPT-1a content and hepatic TAG content. However, the improvement in hepatic lipid metabolism induced by FO was not sufficient to reverse the serum lipid increment found in HFD 
(A)

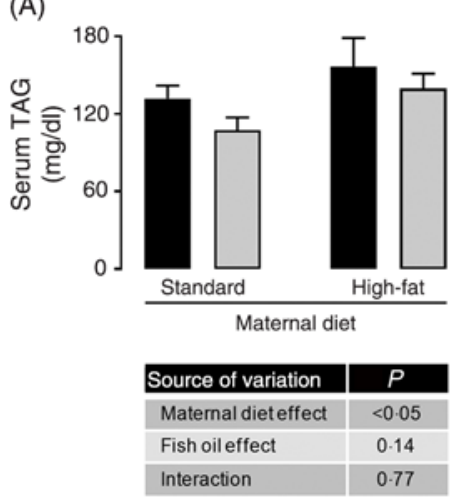

(D)

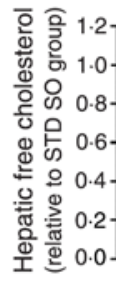

(B)

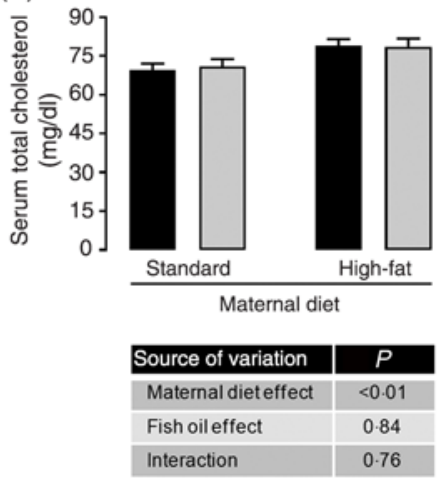

(E)

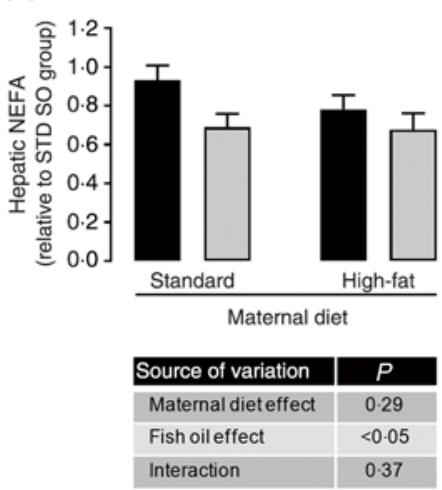

(C)

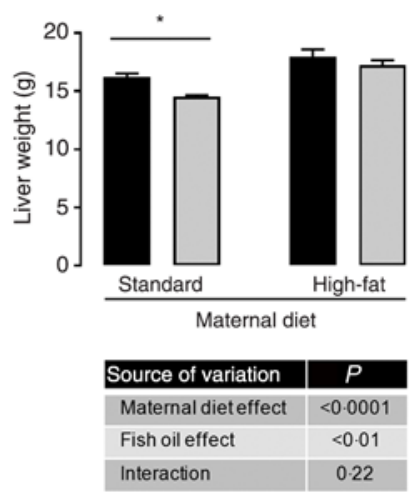

(F)

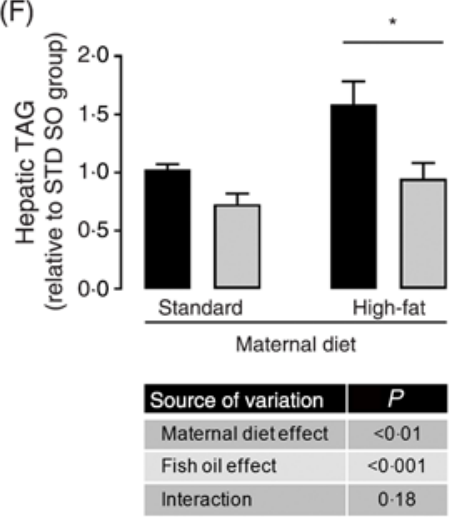

Fig. 3. Effects of fish oil consumption during the adolescence period on serum and hepatic lipid content in adult male offspring from dams that received a standard (STD) or high-fat diet. Offspring received daily oral intervention with soyabean oil (SO; ) or fish oil (FO; ) from 25 to $45 \mathrm{~d}$ of age, and evaluations were performed in adult life (150 d old). (A) Serum TAG. (B) Serum total cholesterol. (C) Liver mass. (D) Hepatic free cholesterol content. (E) Hepatic NEFA content. (F) Hepatic TAG content. Data are means, with their standard errors represented by vertical bars ( $n 9-12)$. Statistical analysis was performed using two-way ANOVA and is described in the table at the bottom of each graph, considering significant differences at $P<0.05$. Tukey's post-test was used to evaluate differences between columns in each maternal condition and results are represented as the bars at the top of the graph. The adjusted $P$ value was ${ }^{*} P=0.0116$ for liver mass (C) and ${ }^{*} P=0.0068$ for hepatic TAG content (D). To convert TAG in $\mathrm{mg} / \mathrm{dl}$ to $\mathrm{mmol} / \mathrm{l}$, multiply by 0.0113 . To convert cholesterol in $\mathrm{mg} / \mathrm{dl}$ to $\mathrm{mmol} / \mathrm{l}$, multiply by 0.0259 .

offspring, suggesting the involvement of other mechanisms or a time-dependent effect.

Hyperleptinaemia and leptin resistance are common outcomes of maternal HFD, as previously observed by our group $^{(7-9)}$ and others ${ }^{(49)}$. In the present study, maternal HFD increased leptin mRNA levels in white adipose tissue in parallel to hyperleptinaemia in adulthood, which were attenuated by FO intake during adolescence. In our model, this leptin regulation might be a result of adiposity changes. However, we are not able to reject the possibility of epigenetic mechanisms involvement. Experimental evidences suggests that epigenetic mechanisms may be involved in the maternal HFD ${ }^{(53)}$ and $n-3$ PUFA $^{(54)}$ impact on leptin regulation in other experimental models.

The JAK2-STAT3 pathway is the major signalling pathway involved in leptin action and its components have been described in the liver ${ }^{(55,56)}$. We have previously described in our model of maternal HFD that there are changes in molecular markers of central leptin resistance in male offspring at weaning and adult life (180 d old $)^{(7,9)}$. However, the peripheral leptin signalling in programming models is poorly known. In the present study, maternal HFD reduced hepatic pSTAT3/ STAT3 ratio, suggesting hepatic leptin resistance in HFD adult offspring. The importance of leptin signalling in liver metabolism was evidenced using a mice model with specific loss of leptin signalling in the liver (deficiency in the leptin-stimulated STAT phosphorylation), which shows hepatic TAG accumulation and serum TAG-rich lipoproteins ${ }^{(55,56)}$. Besides that, STAT3 knockout increases the hepatic TAG content ${ }^{(57)}$. Therefore, the impairment in the activation of the transducer factor STAT3 in the liver of HFD offspring may contribute to hepatic TAG accumulation. Although FO intervention during adolescence attenuated leptin serum levels in adult offspring, it did not change hepatic activation of STAT3. Although $n-3$ PUFA has reversed the increased leptin expression and leptin receptor expression in HFD mice models ${ }^{(22,54)}$, its effect on leptin signalling pathway remains to be elucidate.

In this work, the effects of FO intake exclusively during adolescence were unable to restore all metabolic outcomes from maternal HFD offspring. However, it reverted the hepatic lipid accumulation and it attenuated the metabolic profile even after FO withdraw. These data highlight the potential of the adolescence period in reprogramming the metabolic profile with effects that persist along life. Adolescence is a period with intense neuronal and hormonal changes, essential to normal development, growth, behaviour and reproductive features ${ }^{(58)}$. However, these adaptive changes make adolescence a vulnerable period to epigenetic changes, as result of increased plasticity, modifying the transcriptional activity of many genes and highlighting the interplay between genetic, hormonal and 
(A)

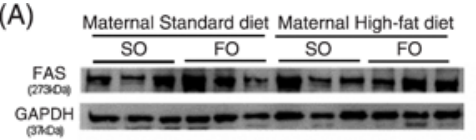

(B) Maternal Standard diet Maternal High-fat diet

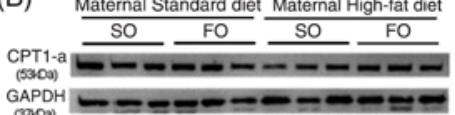

(C)

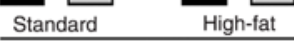

Maternal diet

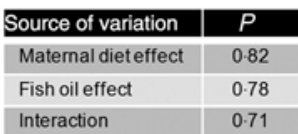

(D)

Hepatic CPT1-a mRNA

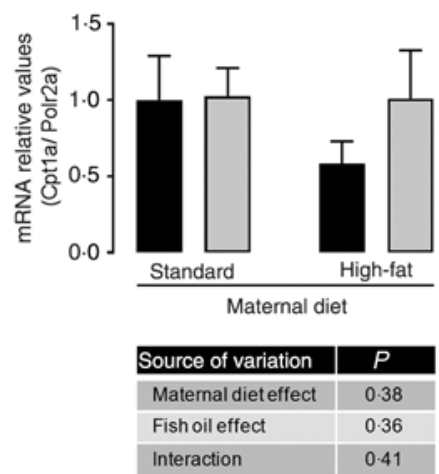

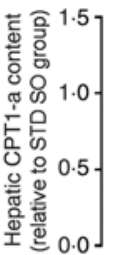

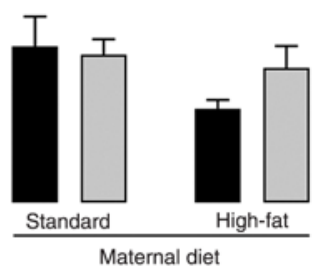

Maternal diet

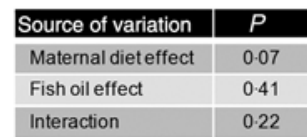

(E)

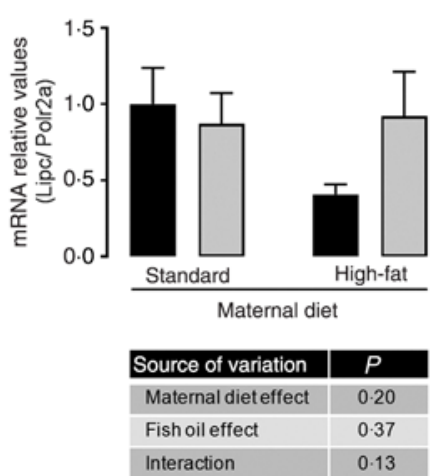

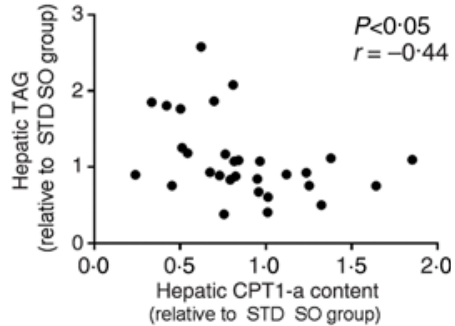

(F) Hepatic PPAR alpha mRNA

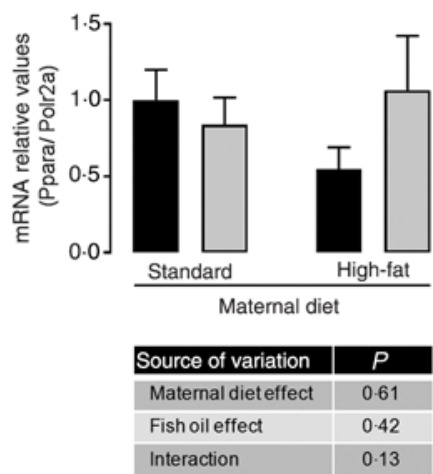

Fig. 4. Effects of fish oil consumption during the adolescence period on hepatic expression of key targets of lipid metabolism in adult male offspring from dams that received a standard (STD) or high-fat diet. Offspring received daily oral intervention with soyabean oil (SO; $\square$ ) or fish oil (FO; ) from 25 to $45 \mathrm{~d}$ of age, and evaluations were performed in adult life (150 d old). (A) Hepatic fatty acid synthase (FAS) protein abundance. (B) Hepatic carnitine palmitoyl transferase-1a (CPT-1a) protein abundance. (C) Correlation among hepatic CPT-1a protein abundance and hepatic TAG content. (D) Hepatic carnitine palmitoyl transferase-1a (Cpt1a) mRNA expression. (E) Hepatic lipase (Lipc) mRNA expression. (F) Hepatic PPAR $($ Ppara) mRNA expression. Data are means, with their standard errors represented by vertical bars ( $n$ 6-9). Statistical analysis was performed using two-way ANOVA and is described in the table at the bottom of each graph, considering significant differences at $P<0.05$. GAPDH, glyceraldehyde-3-phosphate dehydrogenase.

environmental changes ${ }^{(59)}$. Among neuroendocrine changes at this period, leptin is an important connection among central and peripheral metabolism, modulating energy expenditure and food intake, besides others signals such as the reproductive axis $^{(58)}$. In our experimental model, the persistent metabolic effects after FO withdraw suggests epigenetic mechanisms involvement in leptin regulation and other genes of energy metabolism control. This hypothesis is reinforced by a previous study that described FO impact on epigenetic mechanisms such as DNA and histone modifications, by methylation ${ }^{(54,60)}$ and acetylation ${ }^{(61)}$, and non-coding $\mathrm{RNA}^{(62)}$. n-3 PUFA were able to revert leptin promoter modifications promoted by diet-induced obesity (DIO) in mice ${ }^{(54)}$ and to abolish the insulin-induced acetylation on sterol regulatory-element binding protein 1 and cyclo-oxygenase-2 genes in epithelial cells culture ${ }^{(61)}$. These mechanisms were responsible for the down-regulation of leptin expression in DIO mice ${ }^{(54)}$ and down-regulation of lipogenesis and inflammation markers in epithelial cells ${ }^{(61)}$, respectively. Then, these observations suggest putative mechanisms by which FO intake may alter specific epigenetic regulatory processes, impacting in energy metabolism in our experimental model. Nonetheless, a detailed analysis of the regulation of epigenetic markers is needed in the future.

Our main limitation in this work was not identifying the exact molecular mechanism involved in this metabolic reprogramming, and the transgenerational transmission of these new features. However, our observations highlight that perinatal metabolic programming did not promote a definitive metabolic outcome. This metabolic profile of adult offspring is reversible, not only during an intervention along life $\mathrm{i}^{(19,20,63)}$, but even with punctual intervention during the adolescence period. This punctual reprogramming during the adolescence period increases the possibilities to prevention strategies for programmed metabolic syndrome $^{(63)}$.

Therefore, in the present study, we showed that the increased susceptibility to obesity and non-alcoholic fatty liver disease determined by early life events, such as maternal HFD, could be attenuated by interventions during the adolescence period. The intervention only during the adolescence period with FO intake did not affect adiposity and leptinaemia at this period 
of life ${ }^{(8)}$, but it reduced adiposity, serum leptin and restored normal hepatic TAG content in adult life, demonstrating long-term effects. Then, FO intake during adolescence reduced the susceptibility of STD and HFD offspring to obesity and non-alcoholic fatty liver disease development in adulthood. These data suggest that this susceptibility is a result of many epigenetic modifications along life, including perinatal but also the adolescence period $^{(15,64,65)}$, evidencing that maternal choices but also adolescent habits have impact on susceptibility to metabolic disorders in adult life.

\section{Conclusion}

FO consumption exclusively during adolescence programmed STD offspring and reprogrammed HFD offspring male rats to a healthier metabolic phenotype in adult life. The reduction in visceral adiposity, serum leptin and hepatic TAG were the main beneficial FO effects observed in offspring adulthood. These observations highlight the adolescence period as a critical window to prevent or attenuate the long-term metabolic disturbances in the offspring from obese mothers, possibly by reprogramming gene expression and priming for improvement of metabolic outcomes later in life.

\section{Acknowledgements}

This work was supported by Conselho Nacional de Desenvolvimento Científico e Tecnológico (CNPq), Fundação Carlos Chagas Filho de Amparo à Pesquisa no Estado do Rio de Janeiro (FAPERJ) and Coordenação de Aperfeiçoamento de Pessoal de Nível Superior (CAPES). The authors are grateful for technical support from Laboratório de Lípideos - LabLip FCM/UERJ, and for assistance of Luela Dias and Juliana Penna.

This work was supported by Conselho Nacional de Desenvolvimento Científico e Tecnológico (CNPq) (C. C. P.-M., grant no. 305427/2013-0), Fundação Carlos Chagas Filho de Amparo a Pesquisa do Estado do Rio de Janeiro (FAPERJ) (C. C. P.-M., grant nos. 110.108/2013 and 202.924/2015) (L. L. S., grant no. 201.821/2015) and Coordenação de Aperfeiçoamento de Pessoal de Nível Superior (CAPES). The funding agencies had no role in the design, analysis or writing of this article.

A. F. P. S., L. S. O., A. C., E. S. and L. L. S. carried out all animal studies and participated in collection and interpretation of data. A. F. P. S. and L. L. S. performed all experimental procedures and analyses. G. E. G. K. and G. C. A. performed biochemical experiments and analyses. L. L. S., C. C. P.-M. and I. H. T. formulated the research question; they delineated the experimental design and supervised the study. L. L. S. and C. C. P.-M. wrote the manuscript.

The authors declare that there are no conflicts of interest.

\section{References}

1. Popkin BM (2015) Nutrition transition and the global diabetes epidemic. Curr Diab Rep 15, 64.
2. Nicholas LM, Morrison JL, Rattanatray L, et al. (2016) The early origins of obesity and insulin resistance: timing, programming and mechanisms. Int J Obes (Lond) 40, 229-238.

3. Hanson M, Godfrey KM, Lillycrop KA, et al. (2011) Developmental plasticity and developmental origins of noncommunicable disease: theoretical considerations and epigenetic mechanisms. Prog Biophys Mol Biol 106, 272-280.

4. Gluckman PD, Hanson MA \& Buklijas T (2010) A conceptual framework for the developmental origins of health and disease. J Dev Orig Health Dis 1, 6-18.

5. Hanson MA \& Gluckman PD (2014) Early developmental conditioning of later health and disease: physiology or pathophysiology? Physiol Rev 94, 1027-1076.

6. Kirk SL, Samuelsson A-MM, Argenton M, et al. (2009) Maternal obesity induced by diet in rats permanently influences central processes regulating food intake in offspring. PloS ONE 4, e5870.

7. Franco JG, Fernandes TP, Rocha CPD, et al. (2012) Maternal highfat diet induces obesity and adrenal and thyroid dysfunction in male rat offspring at weaning. J Physiol 590, 5503-5518.

8. Oliveira LS, Souza LL, Souza AFP, et al. (2016) Perinatal maternal high-fat diet promotes alterations in hepatic lipid metabolism and resistance to the hypolipidemic effect of fish oil in adolescent rat offspring. Mol Nutr Food Res 60, 2493-2504

9. Franco JG, Dias-Rocha CP, Fernandes TP, et al. (2015) Resveratrol treatment rescues hyperleptinemia and improves hypothalamic leptin signaling programmed by maternal highfat diet in rats. Eur J Nutr 55, 601-610.

10. Latouche C, Heywood SE, Henry SL, et al. (2014) Maternal overnutrition programs changes in the expression of skeletal muscle genes that are associated with insulin resistance and defects of oxidative phosphorylation in adult male rat offspring. J Nutr 144, 237-244.

11. Mischke M, Pruis MGM, Boekschoten MV, et al. (2013) Maternal Western-style high fat diet induces sex-specific physiological and molecular changes in two-week-old mouse offspring. PLOS ONE 8, e78623.

12. Oben JA, Mouralidarane A, Samuelsson A-M, et al. (2010) Maternal obesity during pregnancy and lactation programs the development of offspring non-alcoholic fatty liver disease in mice. J Hepatol 52, 913-920.

13. Krentz AJ, Fujioka K \& Hompesch M (2016) Evolution of pharmacological obesity treatments: focus on adverse side-effect profiles. Diabetes Obes Metab 18, 558-570.

14. Ng M, Fleming T, Robinson M, et al. (2014) Global, regional, and national prevalence of overweight and obesity in children and adults during 1980-2013: a systematic analysis for the Global Burden of Disease Study 2013. Lancet 384, 766-781.

15. Bay JL, Morton SM \& Vickers MH (2016) Realizing the potential of adolescence to prevent transgenerational conditioning of noncommunicable disease risk: multi-sectoral design frameworks. Healthcare (Basel) 4, E39.

16. Birch LL (2006) Child feeding practices and the etiology of obesity. Obesity (Silver Spring) 14, 343-344.

17. Ramaiyan B, Bettadahalli S \& Talahalli RR (2016) Dietary omega-3 but not omega-6 fatty acids down-regulate maternal dyslipidemia induced oxidative stress: a three generation study in rats. Biochem Biophys Res Commun 477, 887-894.

18. Heerwagen MJR, Stewart MS, de la Houssaye BA, et al. (2013) Transgenic increase in $n-3 / n-6$ fatty acid ratio reduces maternal obesity-associated inflammation and limits adverse developmental programming in mice. PLOS ONE 8, e67791.

19. Wyrwoll CS, Mark PJ, Mori TA, et al. (2006) Prevention of programmed hyperleptinemia and hypertension by postnatal dietary omega-3 fatty acids. Endocrinology 147, 599-606. 
20. Hou M, Ji C \& Wang J (2012) The effects of dietary fatty acid composition in the post-sucking period on metabolic alterations in adulthood: can omega3 polyunsaturated fatty acids prevent adverse programming outcomes? J Endocrinol 215, 119-127.

21. Souza LL, Cordeiro A, Oliveira LS, et al. (2011) Thyroid hormone contributes to the hypolipidemic effect of polyunsaturated fatty acids from fish oil: in vivo evidence for cross talking mechanisms. J Endocrinol 211, 65-72.

22. Rossi AS, Lombardo YB, Lacorte J-M, et al. (2005) Dietary fish oil positively regulates plasma leptin and adiponectin levels in sucrose-fed, insulin-resistant rats. Am J Physiol Regul Integr Comp Physiol 289, R486-R494.

23. Couet C, Delarue J, Ritz P, et al. (1997) Effect of dietary fish oil on body fat mass and basal fat oxidation in healthy adults. Int J Obes Relat Metab Disord 21, 637-643.

24. Ukropec J, Reseland JE, Gasperikova D, et al. (2003) The hypotriglyceridemic effect of dietary $n-3 \mathrm{FA}$ is associated with increased beta-oxidation and reduced leptin expression. Lipids 38, 1023-1029.

25. Jump DB (2008) n-3 Polyunsaturated fatty acid regulation of hepatic gene transcription. Curr Opin Lipidol 19, 242-247.

26. Drummond GB (2009) Reporting ethical matters in the Journal of Physiology: standards and advice. J Physiol 587, 713-719.

27. Marques RG, Morales MM \& Petroianu A (2009) Brazilian law for scientific use of animals. Acta Cir Bras 24, 69-74.

28. Zheng J, Xiao X, Zhang Q, et al. (2014) Maternal high-fat diet modulates hepatic glucose, lipid homeostasis and gene expression in the PPAR pathway in the early life of offspring. Int J Mol Sci 15, 14967-14983.

29. Armitage JA, Khan IY, Taylor PD, et al. (2004) Developmental programming of the metabolic syndrome by maternal nutritional imbalance: how strong is the evidence from experimental models in mammals? J Physiol 561, 355-377.

30. Vahratian A (2009) Prevalence of overweight and obesity among women of childbearing age: results from the 2002 National Survey of Family Growth. Matern Child Health J 13, 268-273.

31. Oken E, Rifas-Shiman SL, Field AE, et al. (2008) Maternal gestational weight gain and offspring weight in adolescence. Obstet Gynecol 112, 999-1006.

32. Fischbeck KL \& Rasmussen KM (1987) Effect of repeated reproductive cycles on maternal nutritional status, lactational performance and litter growth in ad libitum-fed and chronically food-restricted rats. J Nutr 117, 1967-1975.

33. Yokomizo H, Inoguchi $\mathrm{T}$, Sonoda $\mathrm{N}$, et al. (2014) Maternal high-fat diet induces insulin resistance and deterioration of pancreatic beta-cell function in adult offspring with sex differences in mice. Am J Physiol Endocrinol Metab 306, E1163-E1175.

34. Reeves PG, Nielsen FH \& Fahey GC (1993) AIN-93 purified diets for laboratory rodents: final report of the American Institute of Nutrition ad boc writing committee on the reformulation of the AIN-76A rodent diet. J Nutr 123, 1939-1951.

35. de Oliveira JC, Gomes RM, Miranda RA, et al. (2016) Protein restriction during the last third of pregnancy malprograms the neuroendocrine axes to induce metabolic syndrome in adult male rat offspring. Endocrinology 157, 1799-1812.

36. Koski KG \& Fergusson MA (1992) Amniotic fluid composition responds to changes in maternal dietary carbohydrate and is related to metabolic status in term fetal rats. $J$ Nutr $\mathbf{1 2 2}$, 385-392.

37. Schneider M (2013) Adolescence as a vulnerable period to alter rodent behavior. Cell Tissue Res 354, 99-106.

38. Reagan-Shaw S, Nihal M \& Ahmad N (2008) Dose translation from animal to human studies revisited. FASEB J 22, 659-661.
39. McNamara RK, Strimpfel J, Jandacek R, et al. (2014) Detection and treatment of long-chain omega-3 fatty acid deficiency in adolescents with SSRI-resistant major depressive disorder. PharmaNutrition 2, 38-46.

40. Sorgi PJ, Hallowell EM, Hutchins HL, et al. (2007) Effects of an open-label pilot study with high-dose EPA/DHA concentrates on plasma phospholipids and behavior in children with attention deficit hyperactivity disorder. Nutr J 6, 16.

41. de Ferranti SD, Milliren CE, Denhoff ER, et al. (2014) Using high-dose omega-3 fatty acid supplements to lower triglyceride levels in 10- to 19-year-olds. Clin Pediatr (Phila) 53, 428-438.

42. Spector AA (1999) Essentiality of fatty acids. Lipids 34, Suppl., S1-S3.

43. Stansbie D, Brownsey RW, Crettaz M, et al. (1976) Acute effects in vivo of anti-insulin serum on rates of fatty acid synthesis and activities of acetyl-coenzyme A carboxylase and pyruvate dehydrogenase in liver and epididymal adipose tissue of fed rats. Biochem J 160, 413-416.

44. Souza LL, Nunes MO, Paula GSM, et al. (2010) Effects of dietary fish oil on thyroid hormone signaling in the liver. $J$ Nutr Biochem 21, 935-940.

45. Friedewald WT, Levy RI \& Fredrickson DS (1972) Estimation of the concentration of low-density lipoprotein cholesterol in plasma, without use of the preparative ultracentrifuge. Clin Chem 18, 499-502.

46. Ortiga-Carvalho TM \& Curty FH (1997) Pituitary neuromedin B content in experimental fasting and diabetes mellitus and correlation with thyrotropin secretion. Metabolism 46, 149-153.

47. Bligh EG \& Dyer WJ (1959) A rapid method of total lipid extraction and purification. Can J Biochem Physiol 37, 911-917.

48. Faul F, Erdfelder E, Lang A-G, et al. (2007) G*Power 3: a flexible statistical power analysis program for the social, behavioral, and biomedical sciences. Behav Res Methods 39, 175-191.

49. Wang H, Storlien LH \& Huang X-F (2002) Effects of dietary fat types on body fatness, leptin, and ARC leptin receptor, NPY, and AgRP mRNA expression. Am J Physiol Endocrinol Metab 282, E1352-E1359.

50. Lima Nda S, de Moura EG, Passos MCF, et al. (2011) Early weaning causes undernutrition for a short period and programmes some metabolic syndrome components and leptin resistance in adult rat offspring. Br J Nutr 105, 1405-1413.

51. Zambrano E, Martinez-Samayoa PM, Rodriguez-Gonzalez GL, et al. (2010) Dietary intervention prior to pregnancy reverses metabolic programming in male offspring of obese rats. $J$ Physiol 588, 1791-1799.

52. Kawano Y \& Cohen DE (2013) Mechanisms of hepatic triglyceride accumulation in non-alcoholic fatty liver disease. $J$ Gastroenterol 48, 434-441.

53. Masuyama H \& Hiramatsu Y (2012) Effects of a high-fat diet exposure in utero on the metabolic syndrome-like phenomenon in mouse offspring through epigenetic changes in adipocytokine gene expression. Endocrinology 153, 2823-2830.

54. Shen W, Wang C, Xia L, et al. (2014) Epigenetic modification of the leptin promoter in diet-induced obese mice and the effects of $n-3$ polyunsaturated fatty acids. Sci Rep $\mathbf{4}, 5282$.

55. Huynh FK, Levi J, Denroche HC, et al. (2010) Disruption of hepatic leptin signaling protects mice from age- and dietrelated glucose intolerance. Diabetes 59, 3032-3040.

56. Huynh FK, Neumann UH, Wang Y, et al. (2013) A role for hepatic leptin signaling in lipid metabolism via altered very low density lipoprotein composition and liver lipase activity in mice. Hepatology 57, 543-554.

57. Inoue H, Ogawa W, Ozaki M, et al. (2004) Role of STAT-3 in regulation of hepatic gluconeogenic genes and carbohydrate metabolism in vivo. Nat Med 10, 168-174. 
58. Avendano MS, Vazquez MJ \& Tena-Sempere M (2017) Disentangling puberty: novel neuroendocrine pathways and mechanisms for the control of mammalian puberty. Hum Reprod Update 23, 737-763.

59. Hochberg Z, Feil R, Constancia M, et al. (2011) Child health, developmental plasticity, and epigenetic programming. Endocr Rev 32, 159-224.

60. Lee H-S, Barraza-Villarreal A, Biessy C, et al. (2014) Dietary supplementation with polyunsaturated fatty acid during pregnancy modulates DNA methylation at IGF2/H19 imprinted genes and growth of infants. Physiol Genomics 46, 851-857.

61. Song N-Y, Na H-K, Baek J-H, et al. (2014) Docosahexaenoic acid inhibits insulin-induced activation of sterol regulatoryelement binding protein 1 and cyclooxygenase- 2 expression through upregulation of SIRT1 in human colon epithelial cells. Biochem Pharmacol 92, 142-148.
62. Li J, Li K, Gao J, et al. (2018) Maternal exposure to an n-3 polyunsaturated fatty acid diet decreases mammary cancer risk of female offspring in adulthood. Food Funct 9, 5768-5777.

63. Mathias PCF, Elmhiri G, de Oliveira JC, et al. (2014) Maternal diet, bioactive molecules, and exercising as reprogramming tools of metabolic programming. Eur J Nutr $\mathbf{5 3}$, $711-722$.

64. Oosting A, Kegler D, Boehm G, et al. (2010) n-3 Long-chain polyunsaturated fatty acids prevent excessive fat deposition in adulthood in a mouse model of postnatal nutritional programming. Pediatr Res 68, 494-499.

65. de Oliveira JC, Lisboa PC, de Moura EG, et al. (2013) Poor pubertal protein nutrition disturbs glucose-induced insulin secretion process in pancreatic islets and programs rats in adulthood to increase fat accumulation. $J$ Endocrinol 216, 195-206. 